\title{
The Diurnal Time Course of Net Photosynthesis of Soybean Leaves: Analysis with a Physiologically Based Steady-State Photosynthesis Model
}

\author{
J.D. Tenhunen, O.L. Lange, P.C. Harley ${ }^{1}$, A. Meyer, and D.M. Gates ${ }^{1}$ \\ Lehrstuhl für Botanik II der Universität Würzburg, Mittlerer Dallenbergweg 64, D-8700 Würzburg, Federal Republic of Germany \\ ${ }^{1}$ The Biological Station and Matthaei Botanical Gardens, Division of Biological Sciences, The University of Michigan, Ann Arbor, Michigan, USA
}

\begin{abstract}
Summary. A physiologically based steady-state model of whole leaf photosynthesis (WHOLEPHOT) is used to analyze observed net photosynthesis daily time courses of soybean, Glycine max (L.) Merr., leaves. Observations during two time periods of the 1978 growing season are analyzed and compared. After adjustment of the model for soybean, net photosynthesis rates are calculated with the model in response to measured incident light intensity, leaf temperature, air carbon dioxide concentration, and leaf diffusion resistance. The steady-state calculations closely approximate observed net photosynthesis. Results of the comparison reveal a decrease in photosynthetic capacity in leaves sampled during the second time period, which is associated with decreasing ability of leaves to respond to light intensity and internal air space carbon dioxide concentration, increasing mesophyll resistance, and increasing stomatal resistance.
\end{abstract}

Several models have been developed (Curry et al. 1975a; Wann and Raper 1979; Heilman et al. 1977) that describe soybean canopy $\mathrm{CO}_{2}$ exchange in relation to intercepted light, temperature, and leaf area index. In some of these, soybean plant growth is simulated, driven by the calculated photosynthetic input. In general, the photosynthetic functions for these models are simple and were established by statistical analysis of whole canopy response characteristics as affected by environmental or plant factors, e.g. leaf distribution, age, and nutrition. Because the scope of such modeling efforts is very broad, encompassing plant growth and even management practices, a certain error resulting from simplification of the photosynthetic input function may not greatly affect the outcome of simulations. On the other hand, some important problems can be studied satisfactorily only with models that allow extrapolation over a wide range of environmental conditions, not all of which are sampled and included during model testing. Models constructed on a physiological-biochemical basis may then be desirable. It may not be possible to simulate the effects of water stress, for example, without considering the detailed response of the plant in controlling behavior at the individual organ level. A second instance, mentioned by Curry et al. (1975b), where more detail must in time be included in crop models, is in the assessment of the effects and consequences of canopy photorespiration under field conditions. With a physiologically based model of leaf photosynthesis, a better understanding of the interactive effects of factors such as light and temperature in determining photosynthesis rates under natural conditions may be achieved.

Detailed analysis of single leaf function in gas exchange is necessary in order to include more physiological reality into the photosynthetic input function of a crop model. In the studies reported here, extensive measurements of carbon dioxide and water exchange of mature fully expanded soybean leaves were made in the field at five minute intervals while simultaneously recording changes in environmental factors influencing leaf response. The gas exchange observations were made with chambers controlled to track naturally occurring variation in air temperature and air humidity. Such methods are necessary since previous work in this laboratory with a wide variety of plants has demonstrated that large errors in estimation of leaf net photosynthetic rate may result when humidity is not controlled (Lange et al. 1969). A continuing effort must be made to reproduce natural conditions, especially since potentially strong humidity responses have been shown for a variety of cultivated plants including soybean (Rawson et al. 1977).

The data were analyzed with a physiologically based model of $\mathrm{C}_{3}$ leaf photosynthesis that has already been used successfully to describe daily time courses of photosynthesis of apricot (Tenhunen et al. 1980). The model may still be improved as more information becomes available, in order to allow for better biochemical and physiological interpretation of the parameters used. Nevertheless, an accurate descriptive model of soybean leaf net photosynthetic gas exchange is obtained, which is sensitive in simulations to small changes in environmental factors, provides a clearer picture of the soybean photosynthetic function, and allows new types of comparisons to be made between the soybean photosynthetic function and that of other species.

\section{Methods \\ Measurements of Gas Exchange}

Soybean plants, Glycine $\max$ (L.) Merr., of P61-22 Peterson variety seedstock from Pioneer Hi-bred, Inc., Waterloo, Iowa, were started in the greenhouse and transplanted to an experimental plot on June 15, 1978 at the Botanical Garden, University of Würzburg. Soybean is not usually cultivated in the Würzburg area. Plants were well watered at all times and were given mineral nutrient solution weekly. No signs of mineral deficiency were observed. Due to low temperatures and low light intensities during June and July, plants grew rather slowly but were robust and sufficiently large by August 1, 1978 that leaves at the top of the canopy could be inserted into gas exchange chambers. Flowering occurred between August 10 and 15. Pod development continued throughout the remaining period of measurement. Due to high rates of net photosynthesis (up to $2.5 \mathrm{nM} \mathrm{CO} \mathrm{Cm}^{-2} \mathrm{~s}^{-1}$ ) entire trifoliate leaves could not be used and observations were restricted to middle leaflets of fully expanded trifoliate leaves that were exposed to full natural light intensities. Carbon dioxide and water exchange were measured 
with temperature and humidity controlled cuvettes operating in parallel as part of a mobile field laboratory previously described (Lange et al. 1969; Koch et al. 1971; Schulze et al. 1972).

The system maintains dew point within the chambers at dew point of the external air by trapping transpired water in a closed loop bypass and maintains air temperature within the cuvette with Peltier heat exchange elements at temperature sensed in the external air. Carbon dioxide concentration, $\left[\mathrm{CO}_{2}\right]$, in the gas exchange chamber fluctuated depending on leaf photosynthetic or respiratory activity and on fluctuation in external air carbon dioxide concentration. At extremely high photosynthesis rates, chamber $\left[\mathrm{CO}_{2}\right]$ decreased as much as $60 \mathrm{ppm}$ below ambient $\left[\mathrm{CO}_{2}\right]$ despite maximal through-flow rates of $250 \mathrm{1} / \mathrm{h}$. External air $\left[\mathrm{CO}_{2}\right]$ was measured continuously during the photosynthesis measurements with an infrared gas analyzer operating in absolute mode. Photosynthetic uptake or release of $\mathrm{CO}_{2}$ by the plant leaf was determined with a second infrared gas analyzer which measured carbon dioxide concentration difference between external and chamber air. Air temperature was sensed with platinum resistance thermometers and leaf temperature with copper/ constantan thermocouples held on the lower surface with a special clamp (Lange and Schulze 1971). Photosynthetically active radiation incident on the leaves was sensed with quantum sensors from LI-COR, Inc. (Lincoln, Nebraska). Rapid changes in photosynthesis and transpiration rates can be observed in response to changes in light intensity or temperature, although it is impossible to remove all time lag from the system (for more detailed discussion see Koch et al. 1971). The extremely rapid responses to passing clouds observed in Glycine required use of the fastest controller settings.

Incident light intensity, leaf and air temperatures, dew points of the incoming bypass, and outgoing air streams, and carbon dioxide gas concentrations were recorded at five minute intervals. Net photosynthesis rates, transpiration rates, and leaf diffusion resistance to water vapor were calculated as described by Lange et al. (1969).

\section{Data Analysis with Photosynthesis Model}

In previous publications (Tenhunen et al. 1976a, b, 1977; Tenhunen and Westrin 1979), the detailed development of a steady-state whole leaf photosynthesis model (WHOLEPHOT) was reported. The model allows calculation of net photosynthetic rate as a function of four independent variables; incident light intensity (PAR), leaf temperature, carbon dioxide concentration, and oxygen concentration $\left[\mathrm{O}_{2}\right]$. Tenhunen and Westrin (1979) discuss the calculation of net photosynthesis rate in response to leaf internal air space $\left[\mathrm{CO}_{2}\right]$. A detailed description of the method in which the model can be applied to daily time courses of net photosynthesis was subsequently presented by Tenhunen et al. (1980) for data from Prunus armeniaca (Lange and Meyer 1979). In this application, stomatal diffusion resistance was included in the calculations and net photosynthesis rates were obtained in response to external air $\left[\mathrm{CO}_{2}\right]$.

In principle, the model WHOLEPHOT was adjusted for the specific photosynthetic characteristics of soybean in the same manner as for Prunus armeniaca. However, as shown in Fig. 1, the apparent photosynthetic capacity, as indicated by maximal net photosynthetic rates attained at midday with equal temperatures and high light intensities, was almost twice as high during the first week of observation as during the next seven weeks. As discussed below, the characteristics of photosynthesis exhibited by these leaves were also different. Simultaneous measurements on other species indicated no change in their photosynthetic capacity or characteristics. Thus, technical imperfections can be excluded as a cause. Since the two sets of observations could not be described with a single version of the photosynthesis equation, two separate fits were obtained. The first fit of the model was restricted to those data where high photosynthetic capacity was exhibited (Model I). A second analysis (Model II) provided a solution of the photosynthesis equation for those data from August 16 to September 25.

To accomplish each fit, a temperature response curve was synthesized from the individual observations by sorting out values of net photosynthesis rate at otherwise constant conditions, i.e. constant light intensity and leaf diffusion resistance. The synthesized response curve was compared with a temperature response curve simulated with the model

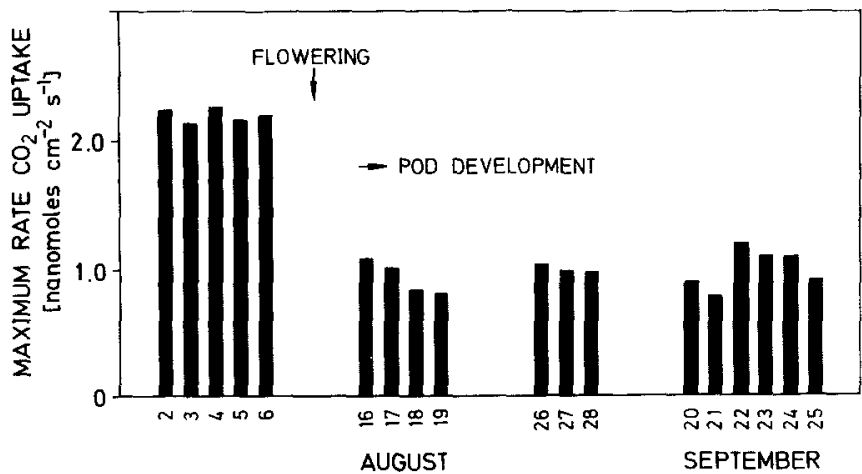

Fig. 1. Maximum daily rates of net photosynthesis observed for soybean leaves during August and September 1978. Maximum rates were usually obtained during the midday period with leaf temperatures between 24 and $28^{\circ} \mathrm{C}$, high light intensities, and low leaf diffusion resistance

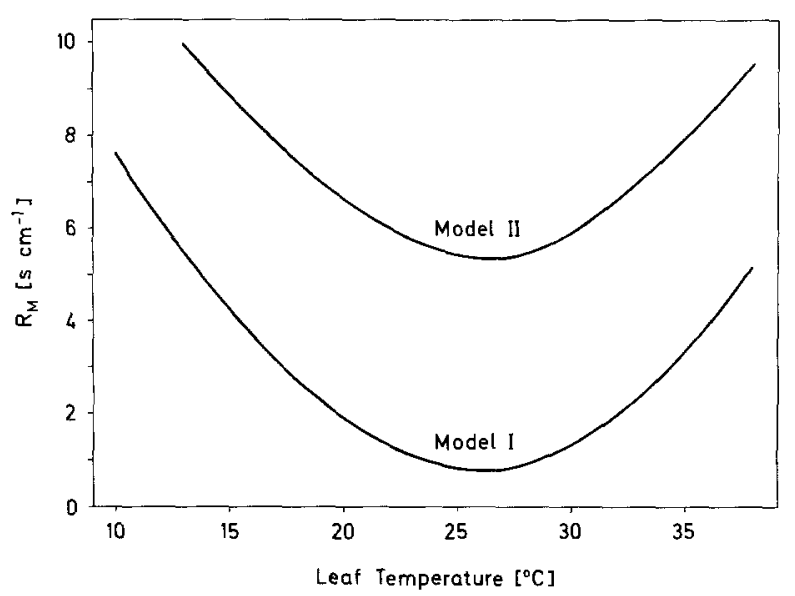

Fig. 2. Mesophyll resistance functions of Eqs. (1) and (2) used in the model Wholephot to calculate net photosynthesis rates

WHOLEPHOT for the same light intensity and diffusion resistance. As with adjustment of the photosynthesis equation for photosynthesis of apricot, only the parameter $P_{\text {MLT }}$ (maximum photosynthetic capacity at saturating light, saturating $\left[\mathrm{CO}_{2}\right], 1 \%$ oxygen, and optimal temperature) and the function providing leaf mesophyll resistance (at $1 \%$ oxygen; $R_{\mathrm{M}}$ ) were altered to obtain the specific photosynthetic characteristics of soybean. $P_{\mathrm{MLT}}$ was changed in magnitude while change in mesophyll resistance resulted as described below from translation with respect to both axes of a parabola providing mesophyll resistance at different temperatures.

To fit the soybean plant behavior during the period of high photosynthetic capacity (Model I), the apricot version of WHOLEPHOT was changed such that the maximum capacity for photosynthesis (parameter $P_{\mathrm{MLT}}$ ) was increased to $5.5 \mathrm{nM} \mathrm{cm}^{-2} \mathrm{~s}^{-1}$ and the magnitude of mesophyll resistance (at $1 \%$ oxygen) was decreased such that:

$R_{\mathrm{M}}=0.028429 T_{\mathrm{x}}^{2}-1.7567 T_{\mathrm{x}}+28.534-0.5$

where:

$R_{\mathrm{M}}$ is in $\mathrm{s} \mathrm{cm}^{-1}$

$T_{\mathrm{L}}$ is leaf temperature $\left({ }^{\circ} \mathrm{C}\right)$

$T_{\mathrm{x}}$ is $\left(T_{\mathrm{L}}+5.0\right)$ and accounts for a shift of five degrees along the temperature axis $\left({ }^{\circ} \mathrm{C}\right)$ in the parabolic mesophyll resistance function adopted from measurements of Doley and Yates (1976).

The equation is written with two constant terms. The first term is that appropriate for the Doley and Yates parabola. The second constant $(-0.5)$ accounts for an additional shift of the original parabola to lower resistance.

To fit the data after August 16 (Model I1), $P_{\mathrm{MLT}}$ was reduced to $4.2 \mathrm{nM} \mathrm{cm}^{-2} \mathrm{~s}^{-1}$ and mesophyll resistance is obtained from: 

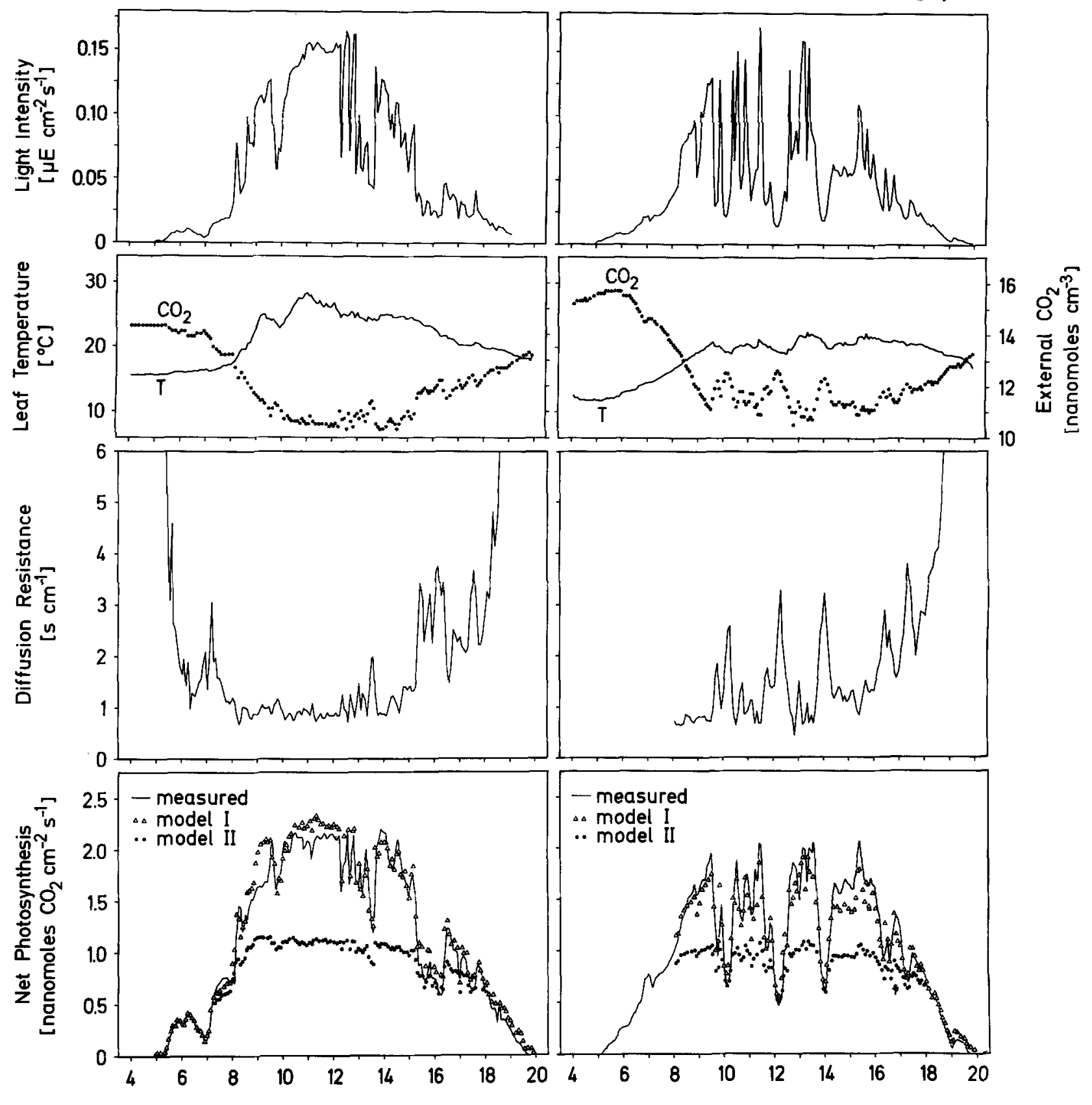

Time [hours]

Fig. 3. Daily time courses of measured environmental and leaf variables affecting net photosynthesis and used as input data to the model (upper three figures in each section) and observed net photosynthesis compared to calculated net photosynthesis rates obtained with Models I and II. Data are shown for August 3 and August 4, 1978 when photosynthetic capacity was high

$$
R_{\mathrm{M}}=0.028429 T_{\mathrm{x}}^{2}-1.7567 T_{\mathrm{x}}+28.534+4.2 \text {. }
$$

The second constant of the equation $(+4.2)$ accounts for shift of the original parabola to higher resistance. The two parabolas from Eqs. (1) and (2) are shown in Fig. 2.

\section{Results of Photosynthesis Measurements}

Daily time courses of measured net photosynthesis are shown in Figs. 3 through 5 (bottom graph solid line) along with the recorded observations of environmental and leaf variables that influence photosynthesis : incident light intensity, leaf temperature, $\mathrm{CO}_{2}$ concentration in the gas exchange chamber, and leaf diffusion resistance for $\mathrm{H}_{2} \mathrm{O}$. The maximum rates of net photosynthesis observed are comparable to rates previously reported for wellwatered soybeans. The rates measured between August 1 and August 8 (Fig. $3 \mathrm{~A}$ and $\mathrm{B}$ ) compare favorably with rates measured by Dornhoff and Shibles (1976), Upmeyer and Koller (1973), and Woodward (1976). The lower rates measured after August 16 (Figs. 4 and 5) are similar to those reported by Vignes and Planchon (1979) for soybeans grown in France.

From the time courses shown, it is apparent that the trend 

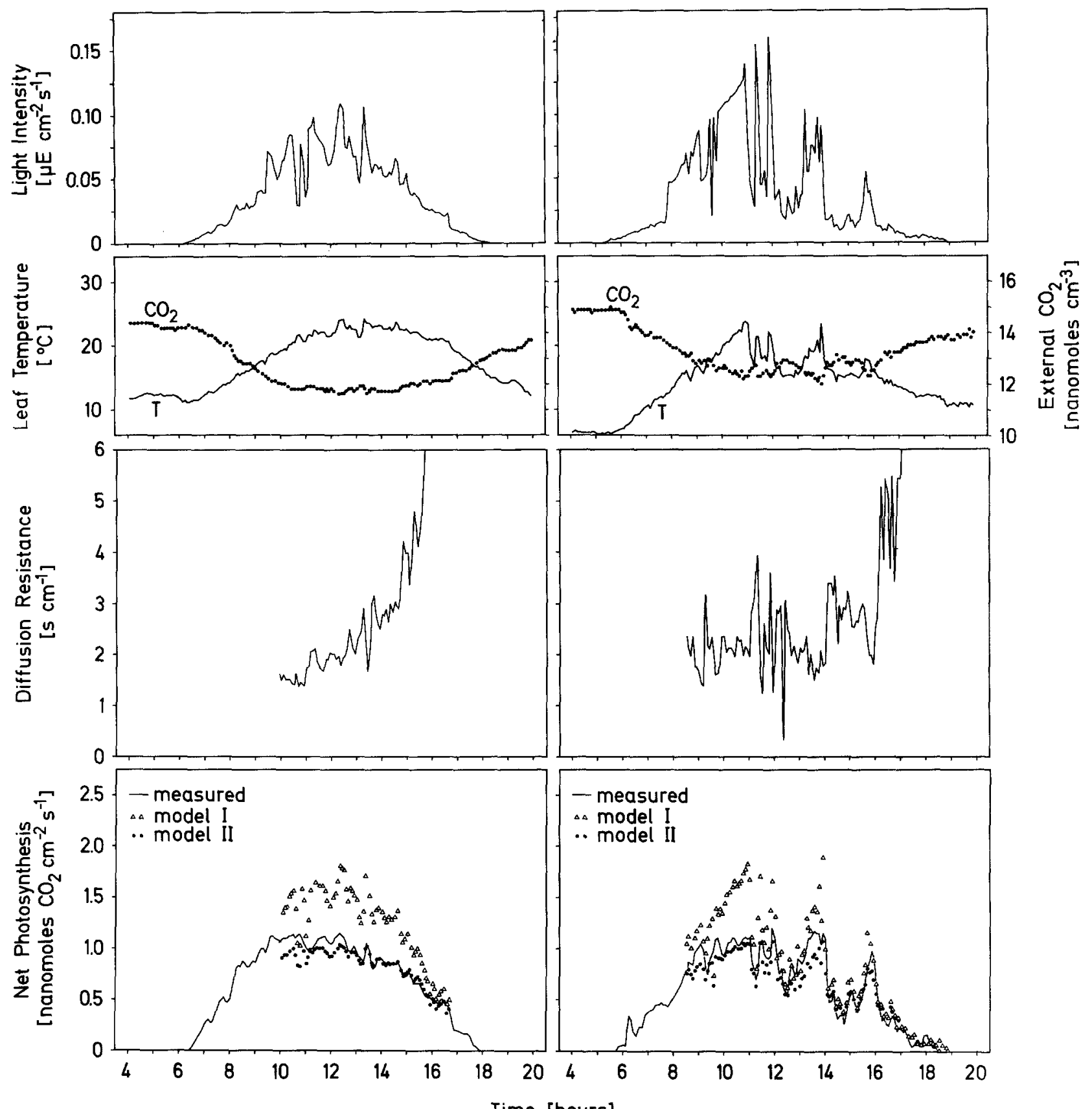

.. model II

Time [hours]

Fig. 4. Daily time courses of measured environmental and leaf variables affecting net photosynthesis and used as input data to the model (upper three figures in each section) and observed net photosynthesis compared to calculated net photosynthesis rates obtained with models I and II. Data are shown for September 24 and August 27, 1978 when photosynthetic capacity was low

in leaf photosynthesis for these well-watered plants is toward dome-shaped responses. Such results have been reported previously as well (Vignes and Planchon 1979; Sinclair et al. 1979). The dome-shaped aspect observed for daily time courses of soybean net photosynthesis is to a great extent a result of a general trend in diurnal stomatal behavior. On all days of observation, minimal stomatal resistance occurred around 10 A.M. Beginning around noon, a gradual stomatal closure was observed that continued until dark. Between 8:30 and 15:00 on September 24 (Fig. 4A), for example, the shape of the net photosynthesis time course is almost entirely determined by a slow closure of stomata. No mid- day closure of stomata was observed but leaf temperatures remained below $30^{\circ} \mathrm{C}$ and dew points were fairly high during the summer of 1978 .

Measurement of net photosynthesis on a five minute basis reveals interesting effects super-imposed on the general trends. As seen in Figs. $3 \mathrm{~A}$ and $\mathrm{B}$, the pattern of net photosynthesis follows measured changes in light intensity. The extreme to which this may occur is seen on August 4 (Fig. 3B) when extremely variable light intensity produced an equally variable photosynthetic response. It appears that net photosynthesis in these leaves is not light saturated even at PAR fluxes of approximately 0.15 


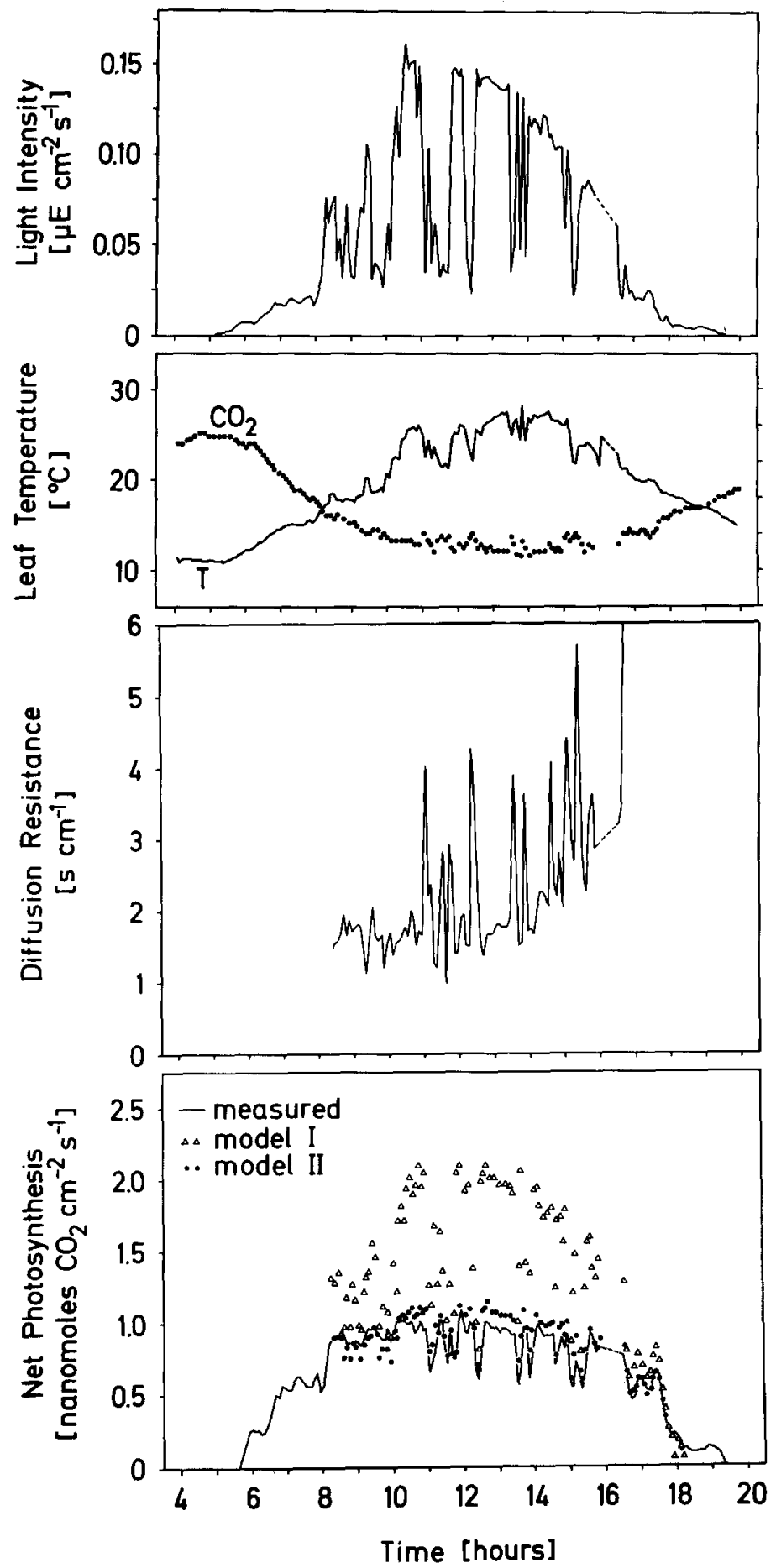

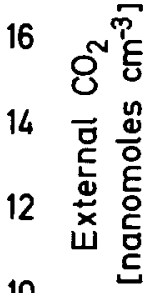

Fig. 5. Daily time courses of measured environmental and leaf variables affecting net photosynthesis and used as input data to the model upper three figures and observed net photosynthesis compared to calculated net photosynthesis rates obtained with models I and II. Data are shown for August 17, 1978 when photosynthetic capacity was low

$\mu$ Einstein $\mathrm{cm}^{-2} \mathrm{~s}^{-1}$. This characteristic sensitivity of net photosynthesis to very high light intensity was seen for all days of observation between August 1 and August 8 . Similar results were observed by Beuerlein and Pendleton (1971) and by Egli et al. (1970) but for soybean canopies rather than leaves. When photosynthetic capacity is high (Figs. $3 \mathrm{~A}$ and $\mathrm{B}$ ), leaf resistance is closely related to both light intensity changes and net photosynthesis rates in an inverse fashion.

During the time period in which photosynthetic capacity was low, i.e. after August 16, a daily pattern for net photosynthesis

was commonly obtained (Fig. 4A) which was little influenced by light intensity fluctuations between 0.05 and $0.15 \mu$ Einstein $\mathrm{cm}^{-2}$ $\mathrm{s}^{-1}$. On the other hand, as shown in Figs. $4 \mathrm{~B}$ and 5, light intensity fluctuations in a lower range $\left(0-0.03 \mu\right.$ Einstein $\left.\mathrm{cm}^{-2} \mathrm{~s}^{-1}\right)$ alter the photosynthetic pattern. Thus, a characteristic decrease in the light saturation level was found in leaves from the second period of observation, along with the change in photosynthetic capacity. The light intensity fluctuations on August 17 (low capacity Fig. 5) were as large as those on August 3 and 4 (high capacity - Fig. 3) and other environmental variable values were similar. 


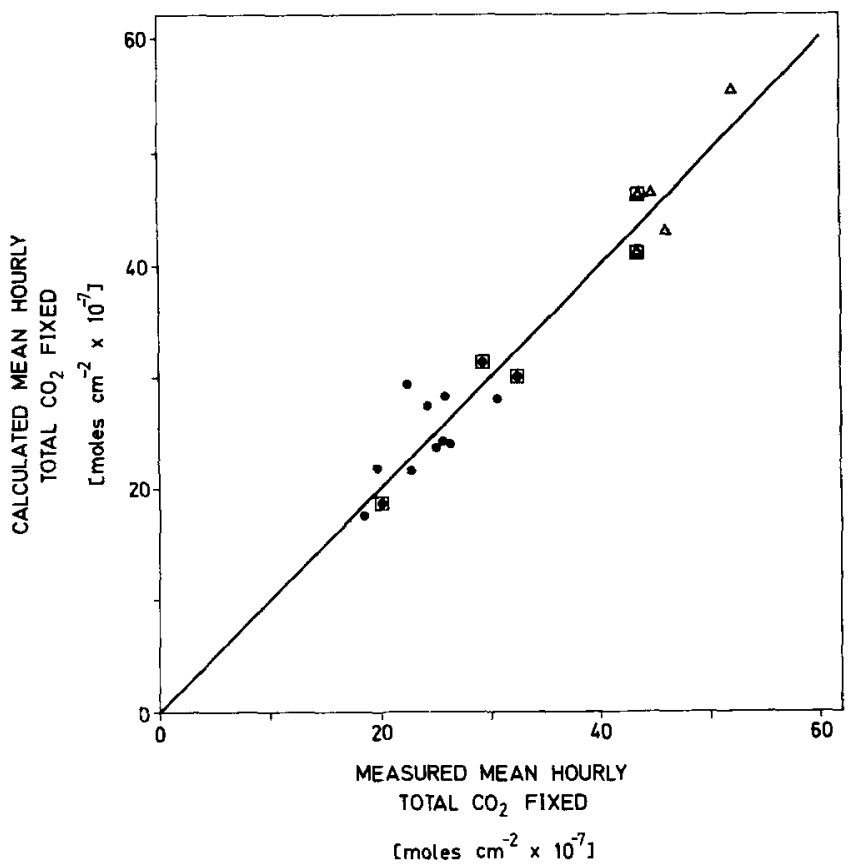

Fig. 6. Integrated net photosynthesis comparison based on observed and calculated rates of net photosynthesis in soybean. Integration is for those time periods in which water exchange data and calculated leaf diffusion resistance were reliable. Triangle symbols represent days with high photosynthetic capacity; solid circles those days with low photosynthetic capacity; boxed symbols are days shown in Figs. 3 through 5 . $r^{2}=0.93$

In addition, the measurements of water exchange indicate that stomatal resistance changes on this day were of the same type as those occuring on August 3 and 4, although minimum resistance is slightly higher. Since on August 17, photosynthesis rates are lower, calculated estimates of $\left[\mathrm{CO}_{2}\right]$ in the air space are greater than on August 3 or 4 for the same environmental conditions. The data are compatible with the interpretation that a true alteration in photosynthetic capacity has taken place reducing the ability of the leaves to respond to both light and internal $\left[\mathrm{CO}_{2}\right]$. The shift in photosynthetic capacity is accompanied by increased stomatal resistance (decreased conductance). The experiments confirm the contention of Wong et al. (1979) that these two factors which influence plant photosynthetic production change in a correlated manner.

\section{Results of Analysis with the Photosynthesis Model}

The equations for calculating net photosynthesis from the model WHOLEPHOT with the input variables incident light intensity $(L)$, leaf temperature $\left(T_{\mathrm{L}}\right),\left[\mathrm{CO}_{2}\right]$ in the gas exchange chamber $\left(C_{\mathrm{A}}\right)$, and leaf diffusion resistance $\left(R^{\text {total }}\right)$ were discussed in detail for apricot (Tenhunen et al. 1980). The only changes for soybean were presented in the methods section. In Figs. 3 through 5, the daily time course of calculated net photosynthesis is shown. The fit of the high capacity version of the model (I) is very good for days from the initial period of observation (Fig. 3), and the low capacity version of the model (II) provides a good fit to data obtained during the second period of observation (Figs. 4 and 5). To demonstrate that the model versions (I and II) provide considerably different rates, we have included both simulation responses in Figs. 3 through 5. From comparison of these calculat- ed time courses, one can see that while the general level of stomatal resistance increases in period II, this alone is not adequate to account for the depression of photosynthesis observed.

To summarize model performance, net photosynthesis rates (Model I for the first, Model II for the second period of time) were integrated for the observed and calculated values during those periods in which water exchange data, and therefore leaf diffusion resistance, were reliable. The integrated values were standardized as mean hourly values and are presented in Fig. 6. The triangle symbols represent individual days of observation during the period with high photosynthetic capacity. The solid circles represent days from the second period of observation with low capacity photosynthesis. Boxed symbols result from data observed on days shown in Figs. 3 through 5. A one to one correspondence between model and observations is closely approximated $\left(r^{2}=\right.$ $0.93)$.

\section{Discussion and Conclusions}

The results that have been presented demonstrate further that the model WHOLEPHOT can be used to effectively describe whole leaf net photosynthesis under field conditions. It can also be used to interpret changes in net photosynthesis in a more complete manner than previously possible. With the limitation that many parameter settings for the photosynthesis model are hypothetical until verified by independent parameter determinations for soybean leaves, analysis of these data suggests that during the observed shift, maximum capacity $P_{\mathrm{MLT}}$ decreases and the level of mesophyll resistance $R_{\mathrm{M}}(1 \%$ oxygen) increases. As seen from the measured data in Figs. 3 through 5, a change in stomatal function may occur simultaneously with change in photosynthetic capacity but altered resistance is not sufficient to account for changes in net photosynthetic rates and characteristics. As has been discussed, the net photosynthesis function itself must be reinterpreted in order to bring predictions in line with observed data.

It is possible that parameters other than $P_{\mathrm{MLT}}$ and $R_{\mathrm{M}}$ in the model WHOLEPHOT may have changed during the shift in net photosynthesis observed in these soybean leaves. Since we still know very little about variation in the basic model parameters, initial attempts to fit the model to field data have considered changes in those parameters for which we have the most information. If a change in $P_{\mathrm{MLT}}$ and $R_{\mathrm{M}}$ actually occurs, then a large part of the change in both parameters might result from a change in carboxylase content of the plant leaves. Peisker (1976) has discussed the theoretical relationship of carboxylase concentration to $P_{\mathrm{MLT}}$ or maximum photosynthetic capacity, and Yocum and Lommen (1975) and Sinclair et al. (1977), its relationship to transfer resistance due to change in the number and distribution of fixation sites.

Laboratory studies of this soybean variety (Harley, unpublished) indicate that measured photosynthetic capacity and measured mesophyll resistance (from $\mathrm{CO}_{2}$ responses with $1 \%$ oxygen) are strongly affected by developmental age. The preliminary data shown in Fig. 7 indicate high maximum photosynthesis rates $\left(P_{\mathrm{ML}}=5.0 \mathrm{nM} \mathrm{cm} \mathrm{s}^{-2} \mathrm{~s}^{-1} ; P_{\mathrm{ML}}\right.$ is an approximation of $P_{\mathrm{MLT}}$, measured at saturating light, saturating $\left[\mathrm{CO}_{2}\right], 1 \%\left[\mathrm{O}_{2}\right]$, and a near optimal temperature of $30^{\circ} \mathrm{C}$ ) at full expansion or leaf age of 21 days decreasing over a period of two weeks to approximately $4.2 \mathrm{nM} \mathrm{cm}^{-2} \mathrm{~s}^{-1}$. Simultaneously $R_{\mathrm{M}}$ at $30^{\circ} \mathrm{C}$ increases (Fig. 7 B) from $1.8 \mathrm{~s} \mathrm{~cm}^{-1}$ to $3.2 \mathrm{~s} \mathrm{~cm}^{-1}$. The values found for leaf age of 21 days $\left(P_{\mathrm{ML}}=5.0\right.$ and $R_{\mathrm{M}}=1.8$ ) agree well with the settings for $P_{\mathrm{MLT}}$ and $R_{\mathrm{M}}$ used in the present investigation in Model I 


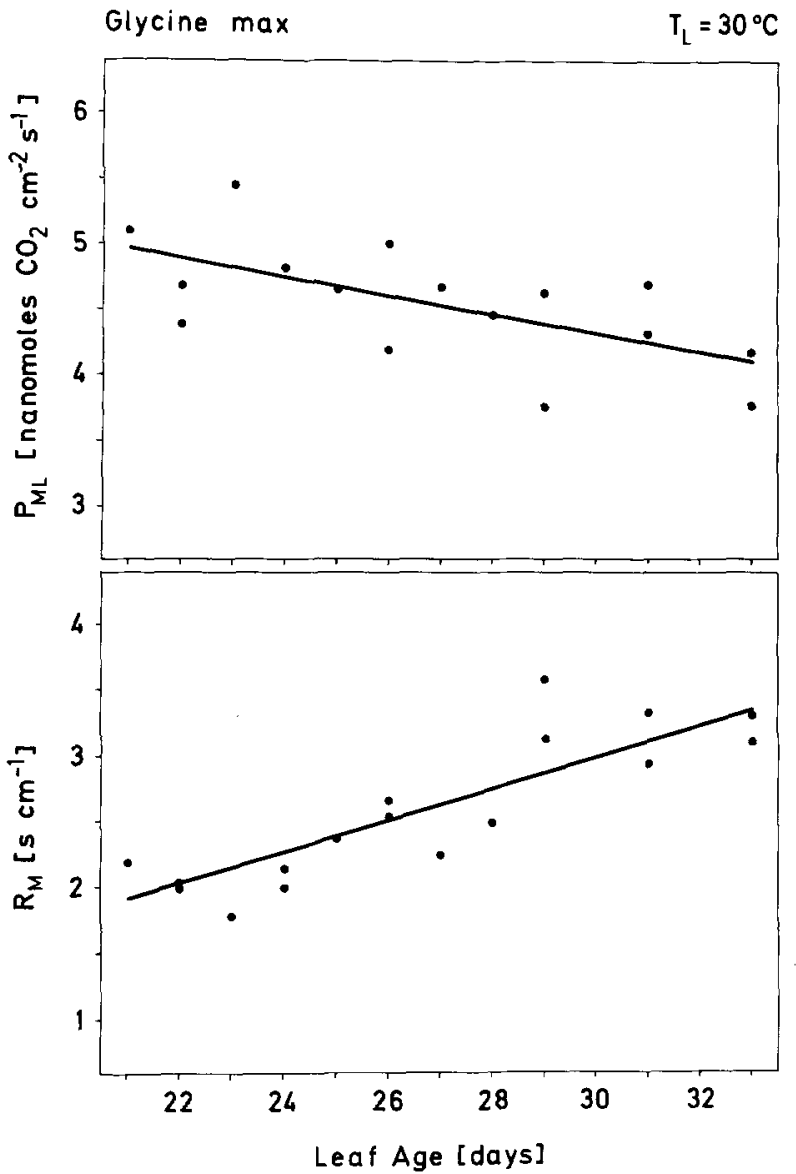

Fig. 7. Measured changes in the parameters $P_{\mathrm{ML}}$ (an approximation of maximum photosynthetic capacity - see text) and $R_{\mathrm{M}}$ (mesophyll resistance from $\mathrm{CO}_{2}$ curves at $1 \%$ oxygen) for soybean leaves as a function of developmental age. Values are obtained from growth chamber grown plants and laboratory photosynthetic measurements

for the period of high photosynthetic capacity. Values shown in Fig. 7 for leaves of 33 day age $\left(P_{\mathrm{ML}}=4.0\right.$ and $\left.R_{\mathrm{M}}=3.5\right)$ are compatible with settings used in Model II for the period of low photosynthetic capacity.

While the variation in parameter values observed in the laboratory provides some confirmation that values for $P_{\mathrm{MLT}}$ and $R_{\mathrm{M}}$ used in the field applications are reasonable, the reason for the sudden change in net photosynthesis rates after August 8 is unclear. It is possible that the initial leaves studied were developmentally younger, and that as vegetative growth slowed, older leaves formed the top of the canopy. More probable, however, is that a developmental change may have been triggered by the onset of flowering and subsequent pod development. A sharp decrease in the absolute level of photosynthesis rate associated with flowering has been reported in several other studies (Woodward 1976; Starck et al. 1979).

Further studies are planned to achieve a better understanding of similarities and differences in photosynthetic behavior of soybean leaves as affected by developmental age and phenology. The photosynthesis model presented provides an effective means of analyzing photosynthetic behavior as the result of changes in meaningful and measurable leaf physiological parameters. By using the model to form and test hypotheses, it is possible to categorize information concerning differences in photosynthetic systems, to search for simplifications by defining those components which remain constant, and to focus biochemical and physiological studies on understanding those parameters which are responsible for greatest variation in photosynthesis. The possibility of deriving a functional dependency for net photosynthesis under field conditions allows new interpretation of leaf phenomena, especially where it is of interest to determine and separate the importance of stomatal function and photosynthesis function in leaf gas exchange.

Acknowledgement. This research was supported by grants from Pioneer Hi-bred, Inc., The National Science Foundation (DEB78-02701), and the Deutsche Forschungsgemeinschaft. The calculations were made at the Rechenzentrum der Universität Würzburg and at the Computing Center of the University of Michigan. Labaratory gas exchange measurements were conducted at the Mathaei Botanical Gardens, University of Michigan.

\section{References}

Beuerlein J, Pendleton J (1971) Photosynthetic rates and light saturation curves of individual soybean leaves under field conditions. Crop Science $11: 217-219$

Curry R, Baker C, Streeter J (1975a) An overview of Soymod, simulator of soybean growth and development. In Proc. 1975 Summer Computer Simulation Conf. p 954-960

Curry R, Baker C, Streeter J (1975b) Soymod I: A dynamic simulator of soybean growth and development. Trans Am Soc Agric Eng $19: 963-968$

Doley D, Yates D (1976b) Gas exchange of Mitchell grass [Astrebla lappacea (Lindl.) Domin] in relation to irradiance, carbon dioxide supply, leaf temperature and temperature history. Aust J Plant Physiol 3:471-487

Dornhoff G, Shibles R (1976) Leaf morphology and anatomy in relation to $\mathrm{CO}_{2}$-exchange rate of soybean leaves. Crop Science 16:377-381

Egli D, Pendleton J, Peters D (1970) Photosynthetic rate of three soybean communities as related to carbon dioxide levels and solar radiation. Agronomy J 62:411-414

Heilman J, Kanemasu E, Paulsen G (1977) Estimating dry matter accumulation in soybean. Proc Amer Met Soc Conf on Agriculture and Forest Meteorology

Koch W, Lange OL, Schulze E-D (1971) Ecophysiological investigations on wild and cultivated plants in the Negev Desert. I. Methods: A mobile laboratory for measuring carbon dioxide fixation and water vapor exchange. Oecologia (Berl) 8:296-309

Lange OL, Koch W, Schulze E-D (1969) $\mathrm{CO}_{2}$-gas exchange and water relationships of plants in the Negev Desert at the end of the dry period. Ber Deutsch Bot Ges 82:39-61

Lange OL, Meyer A (1979) Mittäglicher Stomataschluß bei Aprikose (Prunus armeniaca) und Wein (Vitis vinifera) im Freiland trotz guter Bodenwasser-Versorgung. Flora 168:511-528

Lange OL, Schulze E-D (1971) Measurement of $\mathrm{CO}_{2}$ gas-exchange and transpiration in the beech (Fagus silvatica L). In: Integrated Experimental Ecology, Ecological Studies 2. Springer, Berlin Heidelberg New York., pp 16-28

Peisker M (1976) Ein Modell der Sauerstoffabhängigkeit des photosynthetischen $\mathrm{CO}_{2}$-Gaswechsels von $\mathrm{C}_{3}$-Pflanzen. Kulturpflanze 24:221235

Rawson H, Begg J, Woodward R (1977) The effect of atmospheric humidity on photosynthesis, transpiration, and water use efficiency of leaves of several plant species. Planta 134:5-10

Schulze E-D, Lange OL, Lembke G (1972) A digital registration system for net photosynthesis and transpiration measurements in the field and an associated analysis of errors. Oecologia (Berl) 10:151-166

Sinclair T, Goudriaan J, De Wit C (1977) Mesophyll resistance and $\mathrm{CO}_{2}$ compensation concentration in leaf photosynthesis models. Photosynthetica $11: 56-65$ 
Sinclair T, Johnson M, Drake G, Van Houtte R (1979) Mobile laboratory for continuous, long-term gas exchange measurements of 39 leaves. Photosynthetica $13: 446-453$

Starck Z, Kozinska M, Szaniawski R (1979) Photosynthesis in tomato plants with modified source-sink relationship. Photosynthesis and Plant Development. Dr W Junk, The Hague Boston London

Tenhunen J, Yocum C, Gates D (1976a) Development of a photosynthesis model with an emphasis on ecological applications. I. Theory. Oecologia (Berl) 26:89-100

Tenhunen J, Weber J, Yocum C, Gates D (1976b) Development of a photosynthesis model with an emphasis on ecological applications. II. Analysis of a data set describing the $\mathrm{P}_{\mathrm{M}}$ surface. Oecologia (Berl) $26: 101-119$

Tenhunen J, Weber J, Filipek L, Gates D (1977) Development of a photosynthesis model with an emphasis on ecological applications. III. Carbon dioxide and oxygen dependencies. Oecologia (Berl) $30: 189-207$

Tenhunen J, Westrin S (1979) Development of a photosynthesis model with an emphasis on ecological applications. IV. Wholephot - Whole leaf photosynthesis in response to four independent variables. Oecologia (Berl) $41: 145-162$
Tenhunen J, Meyer A, Lange OL, Gates D (1980) Development of a photosynthesis model with an emphasis on ecological applications. V. Test of the applicability of a steady-state model to description of net photosynthesis of Prumus armeniaca under field conditions. Oecologia (Berl) 45:147-155

Upmeyer D, Koller H (1973) Diurnal trends in net photosynthetic rate and carbohydrate levels of soybean leaves. Plant Physiol 51:871-874

Vignes D, Planchon C (1979) Structure, eclairement et echanges gazeux d'une culture de Soya (Glycine max L. Merr.) Photosynthetica 13:136145

Wann M, Raper C (1979) A dynamic model for plant growth: Adaptation for vegetative growth of soybeans. Crop Science 19:461-467

Wong S, Cowan I, Farquhar G (1979) Stomatal conductance correlates with photosynthetic capacity. Nature 282:424-426

Woodward R (1976) Photosynthesis and expansion of leaves of soybean grown in two environments. Photosynthetica 10:274-279

Yocum C, Lommen P (1975) Mesophyll resistances. Perspectives of biophysical ecology, Ecological Studies 12. Springer, Berlin Heidelberg New York, pp 45-54

Received May 25, 1980 